\title{
DISCURSO PRONUNCIADO POR EL ERIBAJADOR DE LA ARGENTINA Dr. EDUARDO COLOMBES MARMOL
}

\author{
Señor representante del Excmo. Señor Presidente de la República, \\ Señores Ministros Secretarios de Estado, \\ Señor Rector de la Universidad, \\ Señores Embajadores y Ministros, \\ Señores Decanos y Catedráticos, \\ Señoras y Señores:
}

Bajo los auspicios del Exemo. Gobierno Peruano e intermedio del Ministerio de Educación Nacional y por iniciativa del Instituto Cultural Peruano Argentino, esta ilustre Universidad Mayor de San Marcos, de tan altos blasones intelectuales, cuna y foco de nuestra cultura indo-española, cuatro veces centenaria, rinde un solemne homenaje en memoria del ilustre americano y ciudadano de mi patria: DOMINGO FAUSTINO SARMIENTO.

Este patricio de recia y varonil contextura física, como lo veis en su efigie que luce en este salón, y de la formidable envergadura moral descripta por el Sr. Catedrático, Dr. Pedro Dulanto, era como si hubiera sido amasado por la Cordillera y los Ríos paternos con la arcilla pampeana en que se infunde el genio americano; en ese hombre del Ande y de la Pampa, que recibió en su ser el pujante soplo anímico de las dos regiones fundamentales de su tierra, se sintetizan y hermanan las notas caraeteristicas de la indole de la grandeza humana. Su mente clara y lúcida, su visión ámplia y profunda, que abarca y escudriña todo el ámbito de nuestro panorama social y espiritual; su juicio serio y grave, su seasibilidad honda y vibrante, que se desborda en torrentes pasionales y se exalta en frenesíes casi místicos; su voluntad tozuda y tesonera, que infatigablemente se abre paso hacia su meta, salvando o destruyendo obstáculos y tropiezos, como las aguas andinas; su realismo y positivismo, que en nada menguan los vuelos de sus ideales, nos componen, en su retrato moral, la imágen del prócer americano, entre andino y pampeano.

La eurva que señala la vida de Sarmiento, recuerda en sus siruosidades y asperezas, en sus zigzagueos y en su línea quebrada y tormentosa, el perfil de las sierras andinas con sus aristas y sus dentelladuras de piedra, labradas por los ventarrones y desgarradas por los rayos, a cuyo amparo naciera el hijo ilustre de la Provincia de San Juan; pero en su vida, como en esas montañas tutelares, encontramos, al lado del paisaje hozco y ceñudo, de la implacable adustez del páramo y de la solemne majestad de los picos nevados 
y los ventisqueros, la dulzura idílica de los valles y el encanto de otras suaves curvas de las quebradas cordilleranas. Así como alli alterna la tempestad con la inansedumbre y la dicha de la vida ordinaria, es como se diferencian dos de los libros de Sarmiento: FACUNDO, la grandiosa gesta de la Pampa, y RECUERDOS DE PROVINCIA, la crónica sencilla e íntima de sus mocedades en el hogar provinciano. Un tercer libro, de carácter científico, EDUCACION POPULAR, viene a ser como la síntesis de ese antagonismo.

Como todo escritor se revela en sus escritos, por objetivos e impersonales que sean, Sarmiento, cuya obra literaria es fundamentalmente autobiográfica, se muestra de cuerpo entero en esos tres de sus principales libros, que nos relatan los momentos y puntos cardinales de la parábola de su vida y de su carrera: al adolescente estudioso y autodidacto; la juventud del periodista $y$ polemista político, demoledor de la tiranía y del obscurantismo; y la madurez del maestro, que asienta sobre sus cimientos de la educación popular, el edificio de la grandeza nacional.

Al través de sus páginas eseneiales podemos seguir el agitado curso de esa vida, que, a semejanza de los grandes ríos de su territorio, baja torrentaso de las sierras nativas a fecundar, pacíficamente, las pampas y a enriquecer con su aflujo el caudal cultural del Plata.

Sarmiento vivió emigrado durante gran parte del segundo período de su existencia, regresando a la patria cuando el Pronunciamiento de Urquiza, que dió término al estado político y social reinantes hasta 1852 .

Después de Caseros y de luchar con éxito por la unidad nacional, fué elegido Presidente de la República, en 1868 y en circunstancia de encontrarse ausente del país, desde hacía cuatro años, en Lima y en Wáshington, desempeñando el cargo de ministro diplomático, lo que equivale a decir que fué llevado a la primera magistratura de la nación, por imperio de la voluntad popular y sin haber hecho mayor programa de gobierno, del que "estaba en el ambiente", como él mismo lo dijera cuando aceptó la designación de su candidatura.

Sus primeros discursos-mensajes al pueblo, desde la presideneia, llevaban la rareza, para aquella época, de que formulaba "no el viejo $\mathrm{y}$ enardecido mensaje de la asamblea, en la plaza o en el cuartel, sino el tranquilo emplazamiento a la escuela y al colegio".

Su obra de gobierno fué amplísima: primeramente se ocupó de niños y de hombres; de colegios y escnelas primarias y secundarias; de planes de estudio para éstos y para la enseñanza superior del derecho, en la Universidad de San Carlos; fundó la Escuela Naval y el Colegio Militar; organizó el observatorio astronómico y el primer censo nacional; luego las comunicaciones de correos y telégrafos, en las ciudades del interior entre sí y el extranjero. Cuidó la defensa 
nacional; organizó la inmigración, la colonización, la navegación de los ríos y la construcción de puertos; veló por el crédito financiero del país; la construcción de ferrocarriles; organizó exposiciones de artes y productos nacionales; aseguró la moral administrativa; $y$, mientras tanto y sobre todo, fundando escuelas, siempre escuelas y colegios en las ciudades y en la campaña; escuelas en toda la República, para formar maestros y profesores, hasta que se llegó a tener el actual plantel, de dos maestros por cada soldado que sostiene el Estado para custodia de la República; y, para terminar esta relación: Sarmiento, como se ha dicho, coronó su obra "dejando asentado el gobierno nacional, sobre alto e inconmovible pedestal, al abrigo del alzamiento disolvente del caudillo", que tanto anatematizara en Facundo!

Refiriéndose a Sarmiento, el Dr. Pellegrini hizo el siguiente bosquejo:

"Tocóle por patria inmensa heredad inculta, y aplicó todo el vigor de su alma a abrir, en la espesa selva, anchas vías a la civi. lización. Lo hemos visto sudoroso, apasionado, febril, empuñar el hacha del "pionnier", abrirse paso al través del espeso matorral de la ignorancia, destrozando errores, preocupaciones, y al encontrarse en su camino con el árbol colosal de la tiranía, que cubría a su patria toda, con sombra letal, atacar su tronco, herirlo sin tregua y sin reposo hasta verlo caer concestrépito, abriendo en el bosque inmenso claro, que permitió a un pueblo contemplar el cielo luminoso y aspirar las puras brisas de un porvenir libre".

$\mathrm{El}$ acervo aneedótico de la vida de Sarmiento, es riquísimo. Para amenizar esta exposición y enriquecerla objetivamente, en cuanto a que traduzca su inquieto y enérgico carácter, voy a citar algunas:

Respecto de su obra FACUNDO, debo recordar que fué improvisada y escrita en folletín, en mayo de 1845. Mandaba a la imprenta las carillas a medida que se iban llenando, febrilmente, bajo su pluma.

Este libro sin asunto, cuyo interés vive aún, fué traducido entonces al inglés, italiano, francés y alemán. "Era un libro extraño sin piés ni cabeza, informe, verdadero fragmento de peñasco que se lanza a la cabeza de los titanes", según decía el mismo Sarmiento y poniendo en práctica su máxima de toda la vida: "hacer las cosas en el momento oportuno, hacerlas mal, pero hacerlas". 
Un relato de Sarmiento:

"Llegaba de Europa y tomaba yo asiento en una mesa de huéspedes. Estaba allí un personaje, de espíritu travieso, y que no había hecho buenas migas antes con el recién llegado.

"Comían poco menos que en silencio, cuando el taimado, con voz autoritativa $y$ afectando superioridad, dijo:

-Domingo Sarmiento, páseme un plato.

"El al parecer aludido, tuvo sin embargo, la presencia de ánimo de no mover un músculo y como si nada hubiese oído, volver la vista maquinalmente, cuando vió, en efecto, un sirviente traer un plato.

-Mozo! : Es Vd. de San Juan?--Sí, señor.-De Puyuta?.-Sí señor.-Hijo de D. Rafael o de D. Domingo,-De D. Rafael, señor.Vengan acá esos cinco, que es Vd. mi primo; alcance aquella botella del tinto....

En 1849 estaba tan convencido Sarmiento de la próxima caída de Rosas, por un levantamiento de pretorianos, que preparaba una expedición por el lado de Cuyo, haciéndose de recursos en todas las formas imaginables.

Tenemos de labios del Sr. Holmberg, entonces director del jardín botánico de Santiago de Chile, el extraño suceso que sigue.

Como Holmberg oyese un día una algazara de músicas discordantes y gritería de chicuelos, salió a la calle en momentos que se detenía una mascarada con un carro, y un turco de mamarracho, pidiendo limosna para derrocar ta tiranía de Rosas.

El turco se bajó del carro, entró en la quinta para descansar, y sacándose la careta, mostró a los ojos atónitos de su amigo, la cara de Don Domingo Faustino Sarmiento.

El anciano Holmberg no podía contener las lágrimas, cuando esto relataba, y agregaba que nunca le pareció más graude aquel hombre, a quien consideraba el más grande entre todos, como cuando lo vió de turco de mamarracho.

Eduardo Dimet, editor de EL NACIONAL, era grande amigo y sostenedor de la administración y era tal su deseo de no incurrir en pecado venial, siquiera bajo el estado de sitio, que vió al Presidente para que le permitiese enviarle, de antemano, las pruebas de cada número, para no sufrir quebranto ni retardo.

El Presidente contestó que el Gobierno no estaba a medias con nadie, en la responsabilidad de sus actos; que las pruebas de imprenta no constituyen delito, sino la edición y publicación de escri- 
tos sediciosos; que en estado de sitio suprimiría un diario delineuente, pero que para proceder era indispensable que hubiese acto consumado y definido no conato de intención.

Con tales advertencia, EL NACIONAL se miraba a dos lados y mascaba sus palabras antes de lanzarlas; pero un día, el demonio de la publicidad, le hace mandar al traste toda su cautela, y publica una noticia de orden subversivo, llegada por telégrafo y que era falsa.

Sarmiento mandó cerrar la imprenta, hallando, el editor, muy ajustado el castigo a la culpa. Pero pasaban los días sin que se levantara la suspensión y sin encontrar quién se atreviese a abordar al Presidente.

Confiado en sus servicios y amistad, fué a casa de Sarmiento. No bien se hizo anunciar, euando lejos de admitir sus razones, oyó de labios del severo magistrado, la orden de ponerlo preso, inmediatamente, lo que le proporcionó la ocasión de meditar sobre la inutilidad de las amistades, cuando están en pugna con la seguridad social.

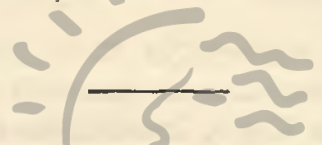

Ardían las pasiones suscitadas por la cuestión San Juan y al trasladarse las cenizas del maestro Peña, el Presidente iba a encontrarse rodeado de sus opositores, entre semblantes hostiles y acaso, tales eran las costumbres, sufrir algún vejámen; pero fué tan imponente la actitud de Sarmiento, descendiendo de su alto magisterio para invocar su título de maestro de escuela, que logró impresionar a sus iracundos oyentes, pudiendo, allevantar la vista a cada período, ver desarrugarse un ceño y cambiarse, lentamente, en expresión de ternura, y asomarse una lágrima en los ojos de gran número.

"Los discípulos son la biografía del maestro y la de Peña está aquí representando sus virtudes:.... Cualesquiera que sean los modos de apreciar mis actos como Presidente, en un punto astoy seguro que están de acuerdo; es que estoy bien al borde de esta tumba, y que mi presencia en este acto ayuda a honrar la memoria. de un maestro.... Acaso la eminencia a que el voto de mis conciudadanos me ha elevado, sea sólo para que sienta más el embate de los vientos $y$ el vano tronar del rayo..... !

En los establecimientos de educación tendía a que fuese abso. Iuta la autoridad del rector, desechando por decreto una petición de alumnos porque la intervención del gobierno relaja la disciplína. Y otra vez telegrafía al Inspector de Colegios: "Las órdenes 
dictadas por el Rector no se revocan. Por regla general los Directores de Colegios tienen razón. Debe Vd. hacer eumplir la orden y después se proveerá lo conveniente, salvando la autoridad moral".

En el Senado, Sarmiento, interrumpe una discusión para una moción de privilegio, a fin de que se investigase un eargo que se le había formulado cuando era Presidente, y que pusiese término a la intervención peligrosa de la barra en las discusiones parlamentarias.

Fué un memorable discurso, variado, profundo y elocuente, que le reconquistó el respeto que se merecía, y euando una intentona de aplausos se produjo, el orador declaró que hacía tanto cáso de los aplausos como de los vituperios.

Para construir un ferrocarril se discutía una ley que garantizaba el interés del $7 \%$ sobre 800.000 pesos que costaría la obra, y cuya cantidad espeluznaba a los legisladores.

No fué aprobada porque se consideraba exorbitante el eventual desembolso.

Sarmiento entonces, le responde a sus colegas del Senado: "-No he de morirme sin ver empleados en ferrocarriles en este país, no digo 800.000 sino 800 millones de duros!

Los senadores $\rceil$ y la barra se echaron a reir, tan insensata les parecía la suma, y Sarmiento pide que conste esa hilaridad en eil acta.

No se equivocó Sarmiento: veinticinco años, después de su muerte, habían 300 millones de libras esterlinas, EL DOBLE de su vaticinio.

Mucho antes de surgir los candidatos para el periodo presidencial de 1880, el Gobernador de Santa Fé, Dr. Simón de Iriondo, escribió a Sarmiento ofreciendo su concurso para elevarlo a la presidencia.

Sarmiento no le contestó.

Pasaron los años y en un día que se encontraron, Iriondo le manifiesta que necesitaba una franca explicación de su silencio. Sarmiento lo lleva a su casa. Llama a su nieto y le dice: "Busca en el "Antonio y Cleopatra", de Shakespeare, la escena del barco y tradúcela al. Dr. Iriondo. Era aquella en que banqueteaban los 


\section{$-384-$}

tribunos rivales Lepidus, Sextus Pompeyo, Harcos Antonio y Octavio, y en medio de la orgía, cuando el esclavo que carga a uno de los borrachos "lleva el tercio del mundo en sus hombros", se acerca Menas a Antonio y le ofrece hacerlo el único dueño del mundo. - "Déjame hundir en el mar a esos tres borrachos y entonces todo será tuyo".

- "Podías hacerlo y no decírmelo! Contesta noblemente el tribuno. En mí sería una infamia, mientras en tí hubiera sido un. buen servicio. Lo hubiera aceptado, pero sabiéndolo, debo condenarlo".

No fué dada otra explicación al Dr. Iriondo.

El que fuera Presidente, en un pueblecito del tránsito a Tucumán, sentado sobre los raigones de un algarrobo atormentado, se vió rodeado de párvulos que lo contemplaban con ojazos confianzudos y candorosos. A una niñita sentada tranquilamente a su lado, que se apoyaba sobre sus rodillas, le preguntó:- ¿Quién soy yo, señorita?.-Es Vd. el padre de los niños argentinos. ¡Es Sarmiento!.

Después de enjugar una lágrima silenciosa, prorrumpió en razones sencillamente expresadas:

- He sido mucho más pobre que Vds. y he luchado con dificultades mucho más terribles que las que nunca conocerán $\nabla d s . \mathrm{He}$ combatido mucho $\mathrm{y}$ muchos años; pero parece que las tempestades se hicieron para que el piloto avanzara más camino; las resistencias, para vencerlas; la envidia, la detracción, para dar testimonio de la verdad honrosa; y sin desviarme de la obra de hacer bien a mis semejantes, he llegado a la cima de la montaña, en la penumbra de esa zona de gloria a que se han encaminado mis pasos. Esto lo comprenderán Vds. más tarde..... !

La obra de Sarmiento como maestro, periodista y gobernante, ha sido brillantemente analizada por el señor Catedrático de Historia de América, de esta Universidad, Doctor Don Pedro Dulante. De mi parte, me he limitado a enunciarla y a bosquejar su temperamento a la luz de algunos pasajes de su vida y a lo que podríamos llamar la trilogía de los libros más substanciosos que escribiera.

En mi carácter de Embajador y ciudadano argentino, presento mi más profundo y cordial agradecimiento al Excmo. Gobierno Peruano, a los Señores Rector, Decano y Catedrático de 


\section{$-385-$}

Historia por su participación en el homenaje a Sarmiento, al cual también lo considero como reiteración de la recíproca simpatía que unen al Perú y Argentina; y a los Excmos. Señores Embajadores y Ministros Diplomáticos, a los Señores Decano y Catedráticos de esta ilustre Universidad, a los señores y las señoras que se han dignado dar realce y adorno a este acto.

He dicho.

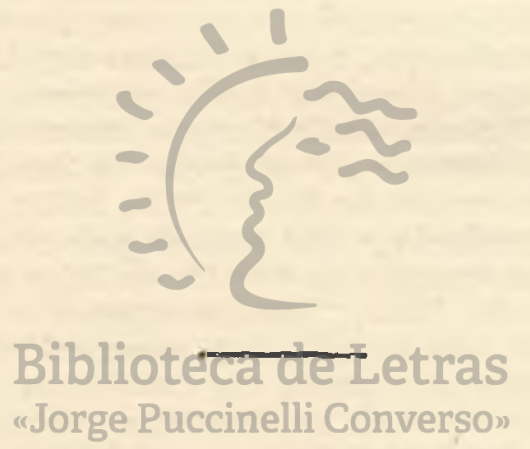

